\title{
Tissue\&Cell
}

\section{Ultrastructure and functional} versatility of hirudinean botryoidal tissue

\author{
M. de Eguileor, ${ }^{1}$ A. Grimaldi, ${ }^{1}$ G. Tettamanti, ${ }^{1}$ T. Congiu, ${ }^{2}$ \\ M. Protasoni, ${ }^{2}$ M. Reguzzoni, ${ }^{2}$ R. Valvassori, ${ }^{1}$ G. Lanzavecchia ${ }^{1}$
}

\begin{abstract}
In leeches, the botryoidal tissue is composed of two different cell types - granular botryoidal cells and flattened endothelial-like cells - localized in the loose connective tissue between the gut and the body wall sac. We have observed that the botryoidal tissue undergoes functional and structural modifications in response to the different needs arising during the life-cycle of the animal. In healthy, untreated leeches, botryoidal cells are organized in cords or clusters, sometimes surrounding few, small lacunae. Conversely, in wounded animals we have observed the transition of the botryoidal tissue from cluster/cord-like structures to a hollow/tubular architecture, typical of pre-vascular structures.
\end{abstract}

We have documented in botryoidal cell cytoplasm the presence of large calcium storage. Moreover, the cytoplasm of botryoidal cells was filled with granules of different form and size, containing iron or melanin, as tested by classic histochemical methods. The presence of elements like iron and calcium was confirmed by the well-established EDS analysis. In response to a surgical wound, botryoidal tissue cells changed their shape and formed new capillary vessels. Concurrently, botryoidal cells secreted iron from cytoplasmic granules into the new cavity: this secretory activity appeared to be related to intracellular calcium fluctuations. At the end of the angiogenic process, botryoidal cells lost their contact with the basal lamina and moved freely in the circulating fluid towards the lesioned area. Interestingly, circulating botryoidal cells were found to carry melanin in the wounded area. This function is probably involved in defense processes.

Thus, we have shown that stimulated botryoidal tissue displays a variety of striking structural, secretory and defensive activities. (C) 2000 Harcourt Publishers Ltd

Keywords: leeches, botryoidal tissue, ultrastructure, histochemistry, EDS analysis

${ }^{1}$ Department of Structural and Functional Biology, University of Insubria, Via J.H. Dunant 3, 21100 Varese, Italy. ${ }^{2}$ Department of Clinical and Biological Science, University of Insubria, Via Monte Generoso 71, 21100 Varese, Italy

Received 29 September 2000

Accepted 7 March 2001

Correspondence to: Magda de Eguileor, Department of Structural and Functional Biology, University of Insubria, Via J.H Dunant 3, 21100 Varese, Italy. Tel: +39 0332 421310; Fax: +39 0332 421300;

E-mail: magda.deeguileor@uninsubria.it

\section{Introduction}

The body of the leech Hirudo medicinalis basically consists of a musculocutaneous sac and a digestive tube. These two systems are separated by a thick layer of loose connective tissue, containing the botryoidal tissue. The botryoidal tissue, characteristic of Arhynchobdellids, is composed of clusters of cells of mesodermal origin.

According to Fischer (1993), the botryoidal tissue has a myelo-erythroid nature, and acts as well as a storage 
compartment for mucopolysaccarides, iron and lipids (Sawyer, 1986). More recently, the involvement of the botryoidal tissue in the formation of new vessels during wound repair processes has been described (de Eguileor et al., 2000b; Tettamanti et al., 2000).

In leeches, in other annelids and in many invertebrates, iron is not stored in red cells as in vertebrates, but is linked to polymeric hemoglobin, freely circulating in body fluids (Needham, 1966; Shlom et al., 1975). According to Fischer (1993), iron secretion is likely to be performed by botryoidal cells.

This study was performed in untreated leeches as well as in wounded animals, in order to investigate the role of botryoidal cells in wound-repair processes. The present study was also aimed at investigating the nature and function of botryoidal cell cytoplasmic granules by histochemical analysis, by transmission (TEM) and scanning electron microscopy (SEM), and by energy dispersive $\mathrm{X}$-ray spectrometry (EDS).

\section{Materials and methods}

Hirudo medicinalis (Hirudinea, Annelida) (from Ricarimpex, Eysines, France) measuring $10 \times 1.00 \mathrm{~cm}$ were kept in water at $22-23^{\circ} \mathrm{C}$ in aerated tanks and were fed weekly with veal liver. Before each experiment, leeches were starved for four weeks. Animals were divided into two different groups: (1) five untreated, control leeches were used to study the body wall organization in normal conditions; (2) 20 leeches (wounded leeches), subjected to lesions consisting of a tissue explant (about $2 \times 2 \times 2 \mathrm{~mm}$ ) affecting the entire body wall. The tissue explant was surgically removed with microdissecting scissors, and wounded leeches were observed $1 \mathrm{~h}$ after surgery.

Before surgical procedures and fixation, leeches were anesthetized with a saturated solution of mephenesin (3$O$-toloxy-1, 2-propanediol), a muscle relaxant.

\section{Light and electron microscopy (TEM and SEM)}

Leeches were dissected and fixed for $2 \mathrm{~h}$ at room temperature in a solution of $2 \%$ glutaraldehyde in $0.1 \mathrm{M} \mathrm{Na}$ cacodylate buffer $(\mathrm{pH} 7.2)$, then washed in the same buffer and postfixed for $2 \mathrm{~h}$ with $1 \%$ osmic acid in $0.1 \mathrm{M}$ Na-cacodylate buffer ( $\mathrm{pH}$ 7.2) at room temperature. After standard step of serial ethanol dehydration, specimens were embedded in an Epon-Araldite 812 mixture. Semi-thin and thin sections were cut with a Reichert Ultracut S ultratome (Leica, Vienna, Austria). Semithin sections $(1 \mu \mathrm{m})$ were stained by conventional methods (crystal violet and basic fuchsin) (Moore et al., 1960), and observed with a light microscope (Olympus, Tokyo, Japan).

Thin sections $(80 \mathrm{~nm})$ were collected on 300 mesh copper grids, stained with uranyl acetate and lead citrate, and observed with a Jeol 1010 EX electron microscope (Jeol, Tokyo, Japan).

Semi-thin sections, thicker than previous described $(3 \mu \mathrm{m})$ were mounted on carbonated stubs, air dried and subsequently covered with a $10 \mathrm{~nm}$ carbon film by flash evaporation of carbon in an Emitech K 250 sputter coater (Emitech, Baltimore, MD, USA). The semi-thin sections were then examined with a SEM-FEG Philips XL-30 microscope (Philips, Eindhoven, Netherlands) in a back-scattered electron mode in order to obtain a morphological picture of the specimens.

The same specimens underwent energy dispersive X-ray spectroscopy (EDS) with an EDAX (EDAX, Mahwah, USA) X-ray spectrometer in mapping mode, in order to visualize the distribution of calcium and iron in the specimen. Photographic maps of element distribution obtained on the image frames were processed by Image Analysis (1994) (Soft-Image Software $\mathrm{GmbH}$ ). These maps were then superimposed to each source image using Photoshop 5.5.

To obtain three-dimensional imaging by SEM, crosssections of the leech body ( $2 \mathrm{~mm}$ thick) from control and wounded animals were subjected to osmic maceration to remove the cytosol, thus facilitating the visualization of cytoplasmic ultrastructure. Samples were then fixed with a solution of $0.25 \%$ glutaraldehyde and $0.25 \%$ paraformaldehyde in $0.1 \mathrm{M}$ Na-cacodylate buffer ( $\mathrm{pH}$ 7.2) for $20 \mathrm{~min}$ at room temperature. Specimens were then washed in $0.1 \mathrm{M}$ cacodylate buffer ( $\mathrm{pH}$ 7.2) and postfixed in a solution of $1 \%$ osmium tetroxide and potassium ferrocyanide for $2 \mathrm{~h}$. Each specimen was cut into slices (thickness: $\sim 0.2 \mathrm{~mm}$ ) and post-fixed in $1 \%$ osmium tetroxide and $1.25 \%$ potassium ferrocyanide for $1 \mathrm{~h}$. Slices were washed in phosphate buffered saline (PBS) (pH 7.2) and then immersed in $0.1 \%$ osmium tetroxide in PBS for $48 \mathrm{~h}$. Slices were subsequently dehydrated in an increasing series of ethanol, subjected to critical point drying with $\mathrm{CO}_{2}$. Dried slices were mounted on stubs, goldcoated with a Sputter K250 coater (Emitech), and observed with an SEM-FEG XL-30 microscope (Philips).

\section{Iron, calcium and melanin cytochemistry}

Reactive ferric iron in semi-thin tissue sections was detected by means of a cytochemical test according to the Perls method, using a histoenzymatic kit (Bio-Optica, Milan, Italy). To reveal the presence of calcium, 6 leeches were fixed in the presence of potassium ferrocyanide according to Forbes et al. (1977). Melanin characterization was performed by destaining semi-thin and thin sections for $5 \mathrm{~min}$ in $10 \%$ and in 3\% hydrogen peroxide, respectively (Pearse, 1972).

\section{$\mathrm{Ca}^{++}$-ATPase ultracytochemistry}

The localization of $\mathrm{Ca}^{++}$-ATPase activity was investigated by ultracytochemistry according to Ando et al. (1981). 

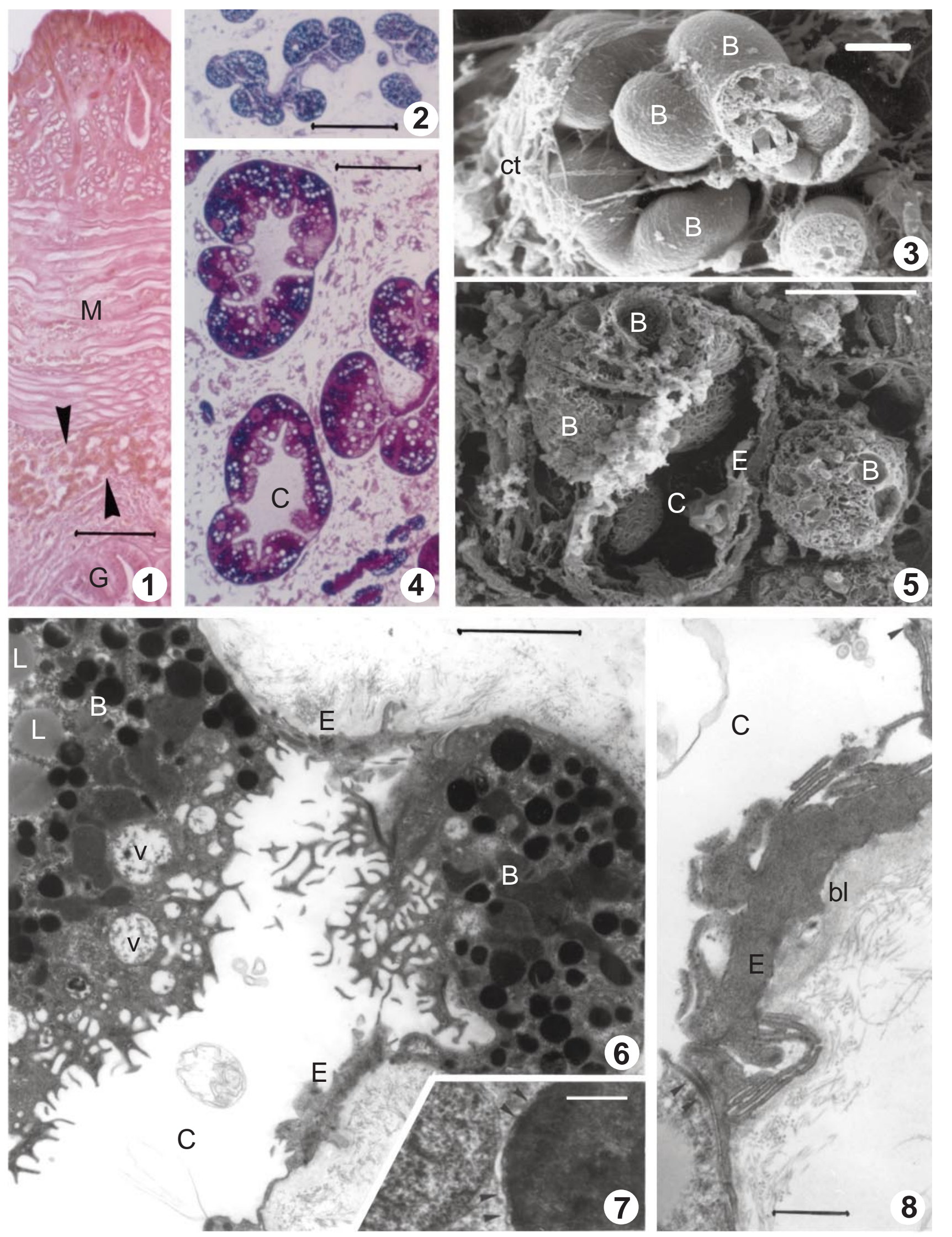

Fig. 1 Paraffin cross-section of control leech. General view of the body of an unlesioned Hirudo. Under the cuticle and epithelia, large layers of muscle tissue (M) are visible. The botryoidal tissue (arrowheads) is localized between muscles and gut (G). Bar, $100 \mu \mathrm{m}$. Fig. 2 Semi-thin cross-section of control leech. The botryoidal tissue is formed by large clustered cells. Bar, $50 \mu \mathrm{m}$. Fig. 3 SEM. The botryoidal cells (B) in a control H. medicinalis, 
are in close contact and are surrounded by a loose connective tissue (ct). Some botryoidal cells are broken, showing the cytoplasmic area (arrowheads). Bar, $5 \mu \mathrm{m}$. Fig. 4 Semithin cross-section. In healthy, untreated leech botryoidal tissue sometimes acquires a lumen and the new small cavities (C) are lined by large granular cells. Bar, $25 \mu \mathrm{m}$. Fig. 5 SEM. Control H. medicinalis. The botryoidal tissue lines new cavities (C). In this case, the fracture shows that the cavity is lined not only by granulated botryoidal cells (B), but also by flattened endothelial-like cells (E). Bar, $5 \mu \mathrm{m}$. Fig. 6 TEM. Control leech. At the early stages of new cavity (C) formation, two different types of cells [botryoidal (B) and endothelial-like (E)] become evident. Botryoidal cell cytoplasm is filled with granules of different sizes, lipid droplets (L) and secretion vesicles (V). Endothelial-like cells (E), localized between botryoidal cells, are smaller and flattened. The starting secretion causes a marked increase of the plasma membrane surface (arrowheads). Bar, $2 \mu \mathrm{m}$. Fig. 7 TEM. Control leech. Detail of a botryoidal granule delimited by a well defined membrane (arrowheads). Bar, $0.2 \mu \mathrm{m}$. Fig. 8 TEM. Unlesioned leech. An endothelial cell linked to a botryoidal cell by junctions (arrowheads), is adjacent to thick basal lamina (bl). C, cavity. Bar, $0.5 \mu \mathrm{m}$.

\section{Results}

\section{Control leeches}

In untreated, control leeches, the botryoidal tissue was localized between the thick muscle layer and the gut (Fig. 1). Botryoidal cell clusters were mostly packed in rope shape (Figs $2 \& 3$ ) or, less frequently, lined to form small lacunae of 10-20 $\mu \mathrm{m}$ (Figs 4-6). The two different organizations were clearly visible with light microscopy, SEM and TEM (Figs 1-6). The botryoidal tissue consisted of two cellular types: botryoidal cells and endothelial-like cells (Fig. 6), linked by desmosome-like junctions and well separated from the connective tissue by a basal lamina (Figs $6 \& 8$ ).

Botryoidal cells were large, roundish or oval when organized in a solid cord, but acquired a semilunar shape when delimiting the lacuna. Their cytoplasm contained numerous, randomly-distributed granules of different sizes and staining properties (Fig. 6). Two different kinds of granules, always contained within a clearly defined membrane (Fig. 7), were observed. Smaller $(400-500 \mathrm{~nm}$ in diameter), electron-dense granules were regular in shape, whereas larger $(800 \mathrm{~nm}$ in diameter), less osmiophilic granules were characterized by a more irregular structure (Fig. 6). Semilunar botryoidal cells bordering the lacunae contained a few large $(1.5 \mu \mathrm{m}$ in diameter) empty cytoplasmic vesicles (Fig. 6). Granules were homogeneously distributed around the nucleus when the botryoidal tissue was organized in ropes, whereas they were arranged close to the basal membrane in cells bordering the lacuna.

Endothelial-like cells were thin, flat and linked with their neighbors by junctions (Fig. 8). Their cytoplasm was poor in organules and granules: nuclei were small and undetectable in most sections (Fig. 8).

\section{Histochemical analysis}

Botryoidal cells were positive to the Perls reaction for the presence of iron. This metal was evidenced as a blue stain by colored salt deposition (Fig. 9). The potassium ferrocyanide technique evidenced the presence of intracytoplasmic calcium (Fig. 10). The small roundish granules disappeared after incubation in hydrogen peroxide (Fig. 11).

\section{$\mathrm{Ca}^{++}$-ATPase ultracytochemistry}

A positive reaction was clearly observed on the membranes surrounding medium-size secretory granules (Fig. 12).

\section{EDS analysis}

EDS analysis was performed in order to confirm the presence of iron and to describe its subcellular compartmentalization. Iron was prevalently localized at one pole of botryoidal cells. In particular, only middle-sized granules contained iron, whereas smaller granules and large vesicles contained iron-free material (Figs 13 \& 14). Iron was also absent in endothelial-like cells. Microanalytical EDS analysis showed that calcium was exclusively intracellular. A strong signal of calcium was diffusely evident only in the cytoplasm of all botryoidal cells (Fig. 15).

\section{Wounded leeches}

The botryoidal tissue of surgically wounded leeches underwent marked changes compared to controls. Botryoidal cells, initially organized in compact clusters, underwent a dehiscence process, ultimately shaping a new cavity (Figs 16 \& 17). In this way, compact cell cords gradually acquired a lumen. An increase in number and size of the lacunae is evident in sections shown in Figures 17, 18 and 20.

During such events, which led to formation of new vessels, the two types of cytoplasmic granules described above were differently processed in botryoidal cells. Middle-sized granules accumulated towards the luminal membrane, and appeared to be massively secreted into newly-formed cavities (Fig. 20). Smaller, electron-dense granules were always visible both in wounded and control leeches, and were prevalently located in the controluminal side of cells (Fig. 20). Massive iron secretion from membrane-wrapped granules caused a marked increase of the plasma-membrane surface. Deep indentations and membrane foldings, clearly visible by TEM and SEM (Figs 18-20), were the morphological evidence of this effect. During this secretion phase, clathrin-coated vesicles, probably associated with membrane trafficking processes, were found to be present in the cytoplasm (Fig. 21). 


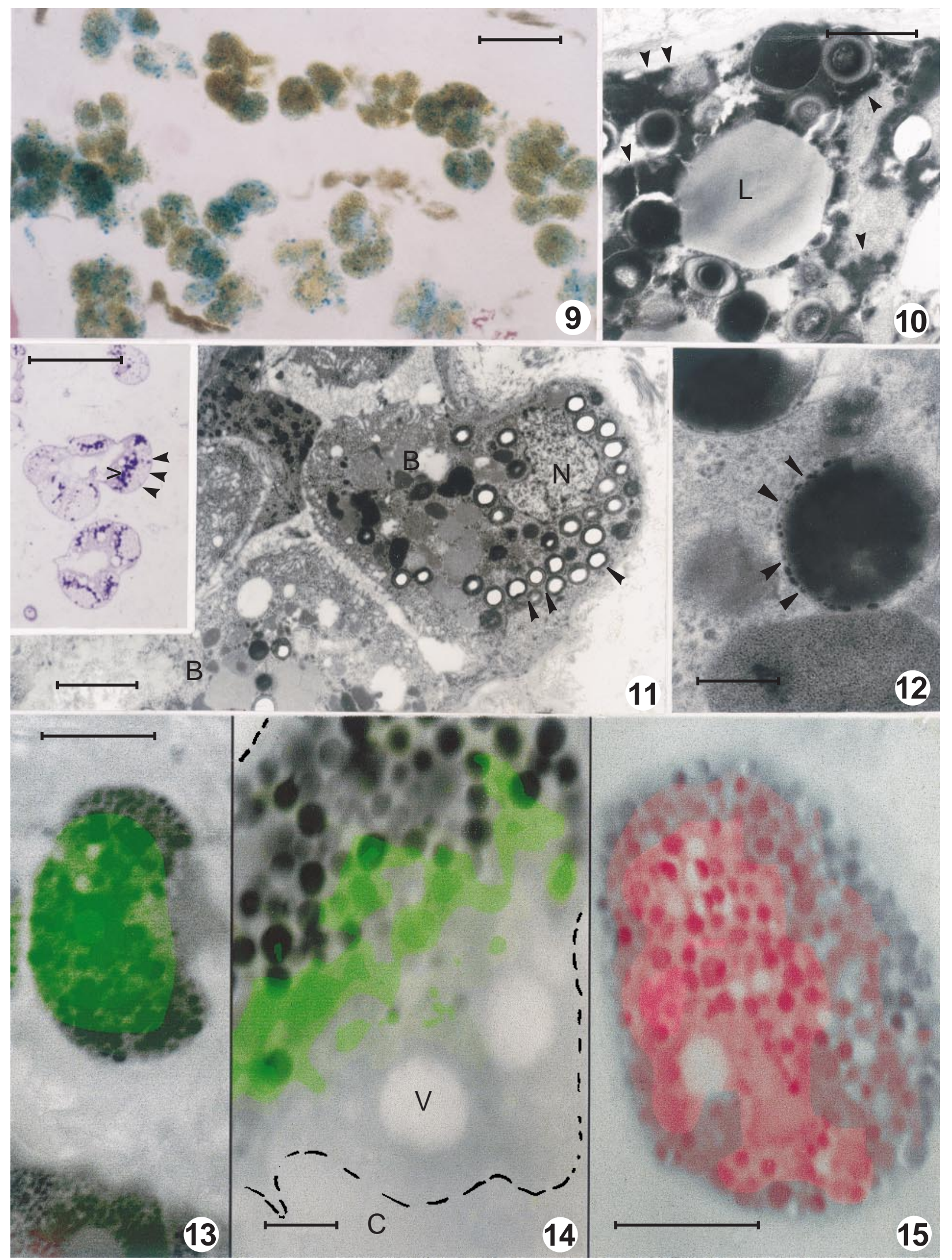

Fig. 9 Semithin section of control H. medicinalis botryoidal tissue. Cytochemical test (Perls method) performed to detect reactive ferric ions (blue). Bar, $50 \mu \mathrm{m}$. Fig. 10 TEM. Control leech. Staining of botryoidal intracytoplasmic calcium storage (arrowheads) by treatment with potassium ferricyanide. Several lipid droplets are visible (L). Bar, $1 \mu \mathrm{m}$. Fig. 11 Control leech. Semithin (left) and thin (right) sections of botryoidal cells incubated for $5 \mathrm{~min}$ in $10 \%$ and $3 \%$, respectively, hydrogen peroxide. Pigment-containing small granules localized in a controluminal position appear destained (arrowheads), suggesting the 
presence of melanin. Other granules, at the luminal side, are not destained (open arrowhead). N, nucleus. Bars, $15 \mu \mathrm{m}, 4 \mu \mathrm{m}$. Fig. $\mathbf{1 2}$ TEM. Control leech. Envelops of medium-sized granules, containing iron, showed intense reaction. $\mathrm{Ca}^{++}$-ATPase was regularly distributed on the membrane (arrowheads). Bar, $0.25 \mu \mathrm{m}$. Fig. 13 Control leech. EDS analysis in unlesioned leech. Iron, marked in green, is detectable in botryoidal cell cytoplasm. The color intensity is in inverse relation to the concentration of the detected element (i.e. a light green area corresponds to a higher iron concentration). Bar, $10 \mu \mathrm{m}$. Fig. $\mathbf{1 4}$ Control leech. EDS analysis. Iron (marked in green) is detectable only in the area where middle-sized granules are localized, whereas it is lacking in smaller granules and vesicles (V). C, cavity. Botryoidal cell profiles are outlined. Bar, $1 \mu \mathrm{m}$. Fig. 15 Control leech. EDS analysis. Calcium (marked in red) is diffusely localized in the cytoplasm of a botryoidal cell. Bar, $5 \mu \mathrm{m}$.

Endothelial-like cells were characterized by a flattened shape and by a cytoplasm filled with small mitochondria, few irregular granules and bundles of intermediate filaments (Figs 22 \& 23). Contacts between adjacent endothelial-like cells, and between endothelial-like and botryoidal cells, were coordinated by desmosome-like junctions (Fig. 21).

\section{Histochemical analysis}

When observed at light microscopy, not only botryoidal cells but also new vessel cavities were positive to the Perls reaction (Fig. 24).

When the tissue was fixed according to Forbes et al. (1977), a massive storage of $\mathrm{Ca}^{2+}$ was evidenced in the cytoplasm of botryoidal cells (Fig. 25).

Interestingly, electron-dense small granules, located at the controluminal side of cell cytoplasm, disappeared after incubation in the presence of hydrogen peroxide (Figs $26 \& 27$ ).

\section{EDS analysis}

In wounded leeches, iron was evident only in rare, middle-sized granules remaining in botryoidal cells after massive secretion (Figs $28 \& 29$ ). The calcium EDS signal was always present, although in variable amounts: this signal could be strong in cells that had not yet degranulated (Fig. 30), but it could be either strong or weak in botryoidal cells that had degranulated (Fig. 31).

\section{Discussion}

The botryoidal tissue, characteristic of leeches like Hirudo medicinalis, is localized in the loose connective tissue between the gut and the body wall sac (Fig. 1). This tissue is physiologically involved in many different functions, including the production of circulating hemoglobin (Needham, 1966; Shlom et al., 1975).

The botryoidal tissue is composed by botryoidal and endothelial-like cells: the former are granular, large and numerous enough to conceal the fewer, smaller, flattened endothelial-like cells, when the tissue is organized into a solid cord (Figs 2 \& 3). However, endothelial-like cells become clearly visible during the formation of prevascular lacunae and, finally, of new blood vessels (Figs $4-6,8,16,17,22)$.

We have shown that the organization of the botryoidal tissue is closely related to the undamaged or wounded condition of the leech: a cluster-like structure with the presence of few lacunae is the common feature of the quiescent botryoidal tissue in control leeches (Figs 2-5), whereas a marked increase in cavity formation, and the shaping of new blood vessels through a remodeling process from solid cords to tubular structures is the typical feature of surgically induced wound repair processes (Figs 16-20, 22).

Since the morphology of endothelial-like cells did not change in control and wounded leeches, we concentrated our attention on botryoidal cells, whose structural and functional organization underwent marked modifications in response to surgical treatment. The shape of roundish botryoidal cells changed dramatically, and became flattened and semilunar, thus increasing the diameter and length of newly forming vessels (Figs 16, 17, 20, 22). Moreover, a parallel, marked decrease of the number of intracellular granules was clearly detectable in surgically-stimulated leeches, when compared to controls. In fact, the decrease in the number of middle-sized, membrane-wrapped granules, was due to the release of their content into forming lacunae: this extensive secretion process led in turn to a considerable enlargement of botryoidal cell plasma membranes (Figs $19 \& 20$ ).

Differences in size and electron density suggested the presence of different components in botryoidal cells cytoplasmic granules. According to the observations of several authors on the functions of the botryoidal tissue (Bradbury, 1959; Mann, 1962; Sawyer, 1986), we tested the presence of elements like iron and calcium in botryoidal cells. Iron and calcium were initially evidenced by classic histochemical methods, even though, in specific cases, published data presented a narrow error margin (Hiraoka \& Hirai, 1992; Zaharopoulos et al., 1998). To avoid error-related ambiguities, the identification of the tested elements was confirmed by reliable EDS analysis. In addition, whereas the Perls reaction was unable to clearly indicate in which kinds of granules iron was actually detectable, EDS analysis identified middle-sized granules as the elective storage sites of this element (Figs 14, 28, 29). These granules were characterized by the presence of regularly distributed membrane-bound $\mathrm{Ca}^{++}$-ATPase (Fig. 12). Interestingly, EDS analysis data suggest that iron secretion may be associated to cytoplasmic calcium fluctuations. This hypothesis is in agreement with several reports demonstrating that increased cytoplasmic calcium enhances cellular secretion in different types of tissues (Douglas \& Poisner, 1963; Case \& Clausen, 1973; Petersen \& Maruyama, 1984; Soji et al., 1991; Rodriguez et al., 1997) 

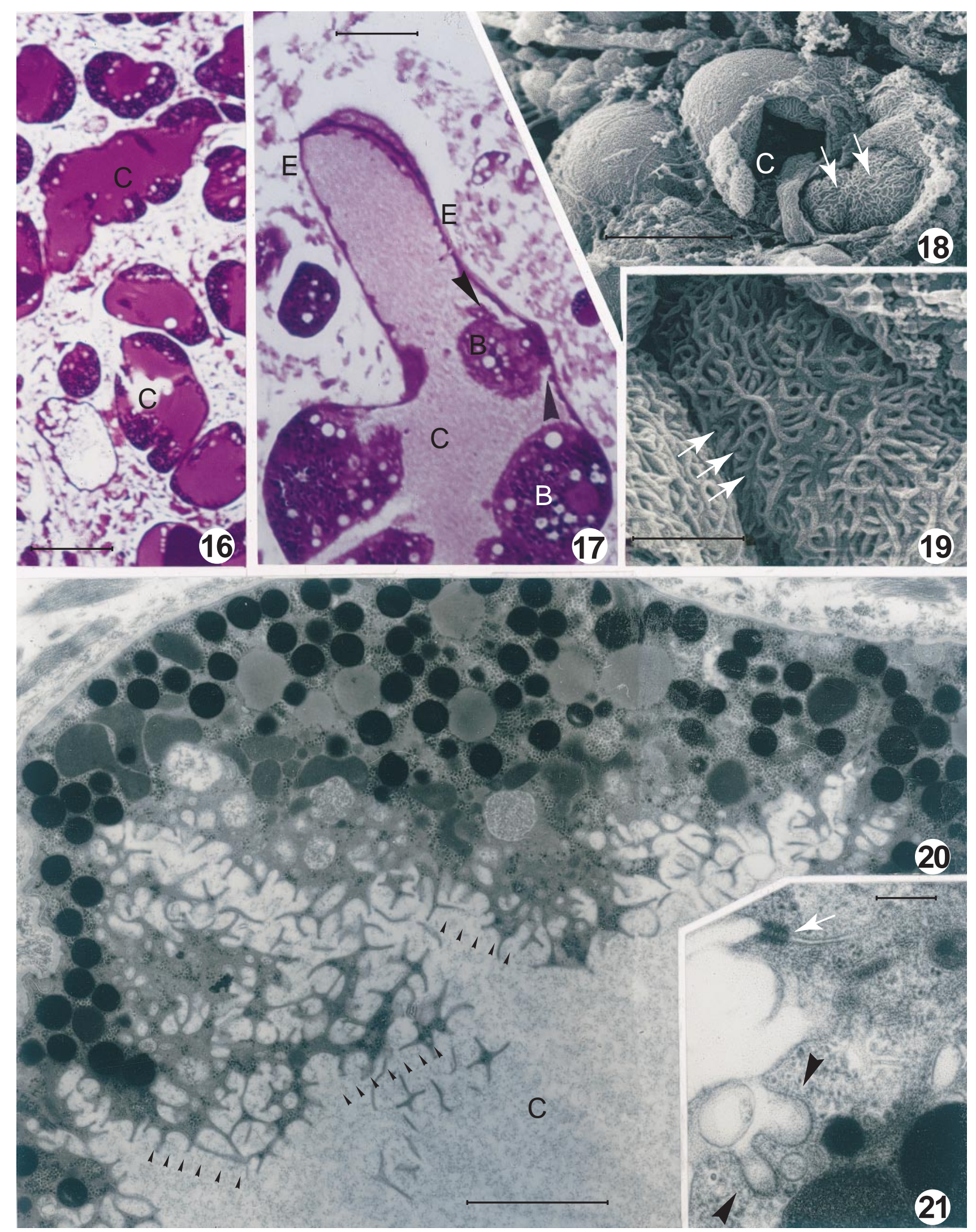

Fig. 16 Semi-thin section of surgically wounded leeches. Botryoidal tissue cells define a new cavity through a dehiscence process (C). Bar, $25 \mu \mathrm{m}$. Fig. 17 Semi-thin section of surgically wounded leeches. The luminal cavity (C), lined by botryoidal (B) and endothelial-like cells (E) has increased in size. Some botryoidal cells have reduced their contact surfaces (arrowheads). Bar, $10 \mu \mathrm{m}$. Fig. 18 SEM. Wounded leech. The botryoidal tissue begins to form the new vessels with a dehiscence process $(\mathrm{C}$, cavity). White arrows indicate the front view of a botryoidal cell after iron secretion. The luminal front of the cells shows a large number of membrane ruffles. Bar, $4 \mu \mathrm{m}$. Fig. 19 SEM. Detail of Figure 18. Membrane ruffles are clearly visible (white arrows). Bar, $2 \mu \mathrm{m}$. Fig. 
20 TEM. Wounded $H$. medicinalis. Botryoidal cells acquire a flattened shape. Cells are concurrently involved in a massive extrusion of large iron granules into the new vessel cavity (C). The secretion process leads to an enlargement of membranes (arrowheads), which corresponds to the 3-D SEM picture of Figure 19. Bar, $2 \mu \mathrm{m}$. Fig. 21 Detail of contact area between two botryoidal cells linked by desmosome-like junctions (white arrow) and of newly forming clathrin-coated vesicles (arrowheads). Bar, $0.2 \mu \mathrm{m}$.
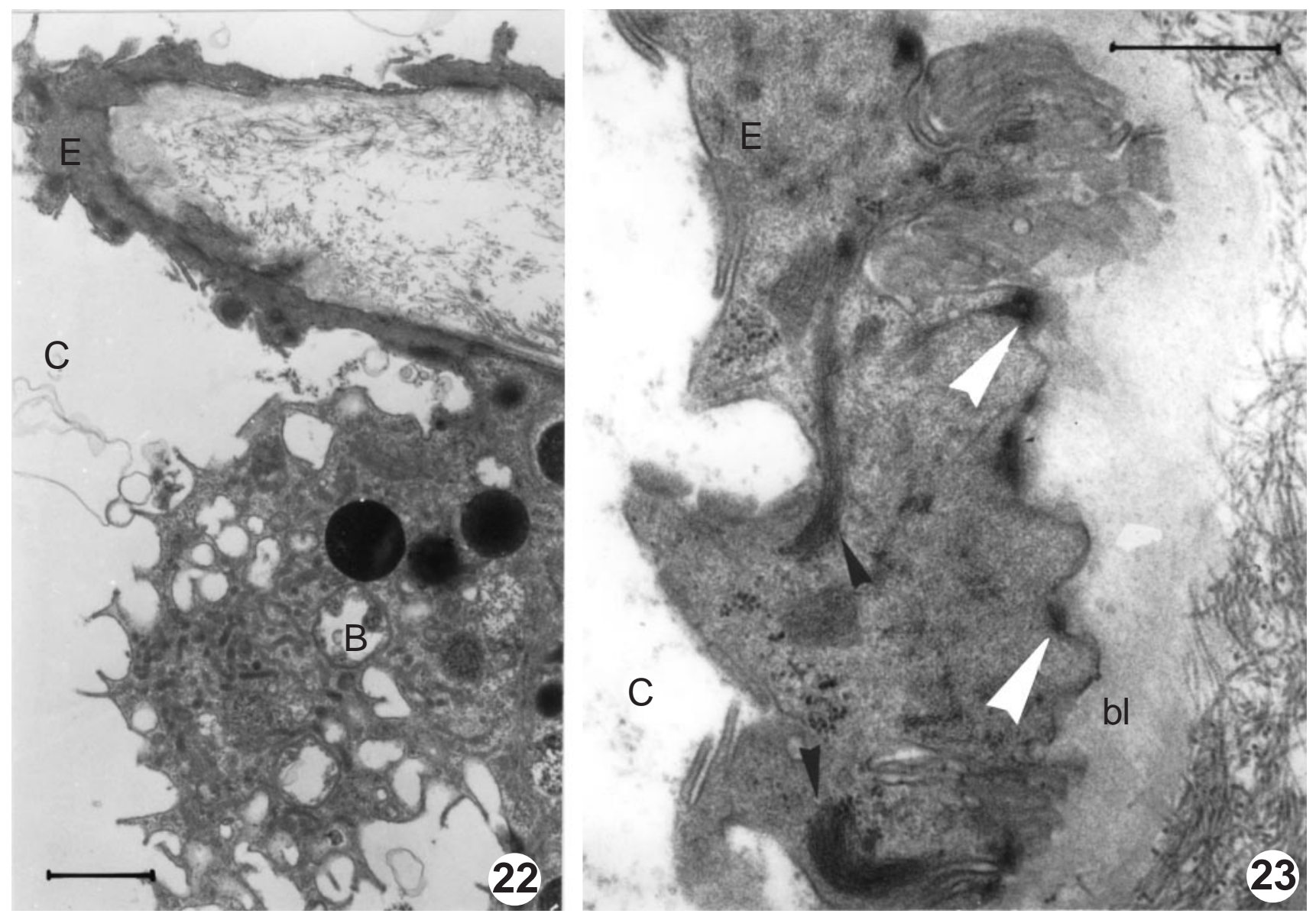

Fig. 22 In wounded leeches the formation of a vessel cavity $(\mathrm{C})$ is due to a flattening, lengthening and stretching of botryoidal (B) and endothelial-like cells (E). Bar, $1 \mu \mathrm{m}$. Fig. 23 Detail of an endothelial-like cell defining the new cavity (C). The cytoplasm is filled with filament bundles (arrowheads). Hemidesmosomes (white arrowheads) are visible at the controluminal side, close to a thick basal lamina (bl). Bar, $0.5 \mu \mathrm{m}$.

The intracellular localization of iron and calcium varied in relation to changing secretion phases. Botryoidal cells in control, unlesioned, leeches contained numerous middle-sized iron granules. In these cells, calcium was predominantly stored in the cytoplasm (Figs 15, 30, 31). As expected, in wounded leeches, botryoidal cells were degranulated and depleted of EDS-detected iron and calcium. However, in some cases degranulated, irondepleted botryoidal cells were shown to contain varying amounts of calcium in the cytoplasm (Fig. 31). As a tentative explanation for this phenomenon we speculate that calcium could be re-uptaken in degranulated cells immediately after iron secretion.

After massive secretion, only small, electron-dense granules, localized at the controluminal side, were visible in botryoidal cells (Figs $28 \&$ 29). These granules were negative for calcium and iron at EDS analysis, and disappeared only after exposure to hydrogen peroxide. We believe that melanin is the major component of these granular structures (Figs 11, 26, 27). Melanin granules play a very important role in the annelid immune system: several authors have shown that this pigment is utilized to isolate macro-antigens (Porchet-Henneré, 1990; PorchetHenneré \& Vernet, 1992; Bilej, 1994; de Eguileor et al., 2000a). In fact in anellids, like polychaets, coelomic granulocytes $\left(\mathrm{G}_{2}\right.$ subpopulation) (Porchet-Henneré \& Vernet, 1992), can release their melanin granules close to a foreign body, thus starting the process of encapsulation and melanization.

By integrating our data with those of other authors (Mann, 1962; Sawyer, 1986; Fischer, 1993), we conclude that the diverse functions of botryoidal cells are related to the varying physiologic demands occurring during the life-cycle of leeches. The activity of the botryoidal tissue became particularly efficient following extensive explantation or deep surgical wounding. In such cases, the cells 


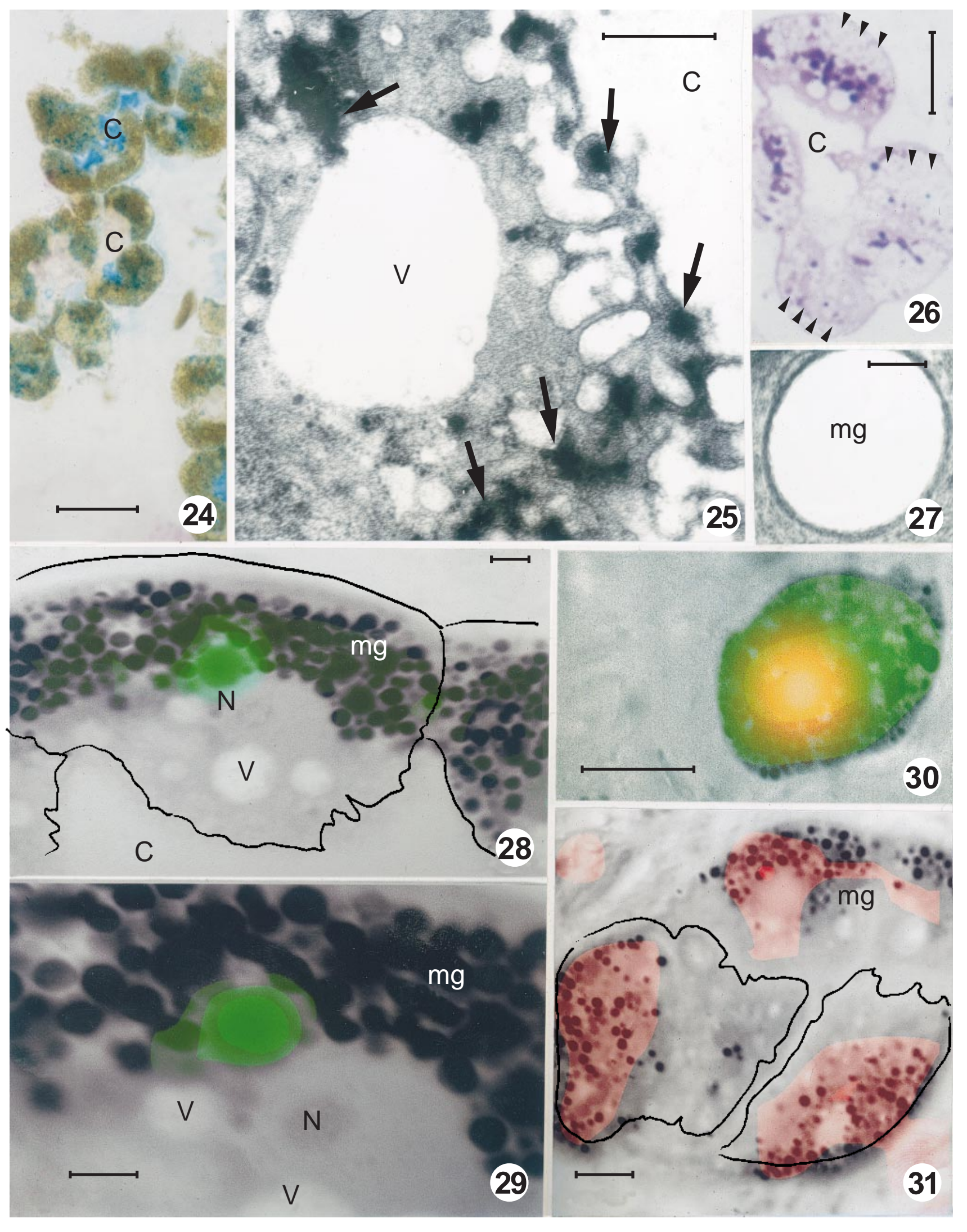

Fig. 24 Semithin section of wounded H. medicinalis. Ferric ions (blue), localized in botryoidal cells and in the lumen cavity (C), are detected by Perls method. Bar, $25 \mu \mathrm{m}$. Fig. 25 Wounded H. medicinalis. Staining of botryoidal intracellular calcium (arrowheads) according to the Forbes technique. No calcium storage is detectable in vesicles (V). C: cavity. Bar, $0.5 \mu \mathrm{m}$. Fig. 26 Surgically wounded leech. Semithin section of a newly-forming vessel at an early stage of development. Only small controluminal granules (arrowheads) are destained after treatment with hydrogen peroxide. Bar, $10 \mu \mathrm{m}$. Fig. 27 TEM. Detail of a melanin granule (mg) after treatment with hydrogen peroxide. Bar, $0.2 \mu \mathrm{m}$. Fig. 28 Wounded leech. EDS analysis. A botryoidal cell has secreted 
all iron-containing middle-sized granules: melanin granules are still present in the cytoplasm. The iron signal (marked in green) confirms the presence of the element exclusively in middle-sized granules. C, cavity; mg, melanin granules; N, nucleus; V, vesicle. Botryoidal cell profiles are outlined. Bar, $1 \mu \mathrm{m}$. Fig. 29 Wounded leech. EDS analysis. Detail of Figure $28 \mathrm{mg}$, melanin granules; N, nucleus; V, vesicles. Bar, $1 \mu \mathrm{m}$. Fig. 30 Wounded leech. EDS analysis. A botryoidal cell that has not yet secreted middle-sized granules, as shown by green iron staining. Calcium (red mark) is also detectable in the cytoplasm. Bar, $10 \mu \mathrm{m}$. Fig. 31 Wounded leech. EDS analysis. Calcium (marked in red) can be detected in botryoidal cells that have just underwent a secretion process, as confirmed by the presence of melanin granules $(\mathrm{mg})$. The profile of botryoidal cells is outlined. Bar, $2.5 \mu \mathrm{m}$.

contained in the botryoidal tissue (endothelial-like cells as well as botryoidal cells) changed their shape and underwent morphologic and functional changes, ultimately leading to the formation of new capillary vessels. These phenomena were accompanied by massive iron secretion, which may be regulated by calcium stored in the cytoplasm of botryoidal cells. Subsequently, the contact areas of botryoidal cell membranes with the basal lamina decreased up to complete detachment (Fig. 17). Botryoidal cells, now containing only melanin granules, could move freely in the circulating fluid, and could be 'piped' towards the lesioned areas, where melanin might be utilized in defense processes.

In conclusion, the data presented in this paper have provided further evidence that stimulated botryoidal tissue is surprisingly versatile, and performs important structural, secretory and defensive functions.

\section{ACKNOWLEDGMENTS}

We are grateful to Maria Luisa Guidali for her excellent technical assistance.

\section{REFERENCES}

Ando, T., Fujimoto, K., Mayahara, H. and Ogawa, K. 1981. A new one-step method for the histochemistry and cytochemistry of $\mathrm{Ca}^{++}$-ATPase activity. Acta Histochem. Cytochem. 14, 705-709.

Bilej, M. 1994. Cellular defence mechanism. In: Vetvicka, V., Sima, P., Cooper, E.L., Bilej, M. and Roch, P., eds. Immunology of Annelids. CRC Press, Boca Raton, pp 176-200.

Bradbury, S. 1959. The botryoidal and vaso-fibrous tissue of the leech Hirudo medicinalis. Q. J. Microsc. Sci., 100, 483-498.

Case, R.M. and Clausen, T. 1973. The relationship between calcium exchange and enzyme secretion in the isolated rat pancreas. J. Physiol., 235, 75-102.

de Eguileor, M., Grimaldi, A., Tettamanti, G, Valvassori, R. and Lanzavecchia, G. 2000a. Different types of foreign antigens by leech leukocytes. Tissue \& Cell, 32, 40-48.

de Eguileor, M., Grimaldi, A., Tettamanti, G., Palazzi, M., Valvassori, R. and Lanzavecchia, G. 2000b. Allo- and Xeno-graft in Hirudo medicinalis. XVIIIth (New) International Congress of Zoology, Athens, Greece.
Douglas, W.W. and Poisner, A.M. 1963. The influence of calcium in the secretory response on the submaxillary gland to acetylcholine or to noradrenaline. J. Physiol., 165, 528-541.

Fischer, E. 1993. The myelo-erythroid nature of the chloragogenouslike tissues of the annelids. Comp. Biochem. Physiol., 106A, 449-453.

Forbes, M.S., Plantholt, B.A. and Sperelakis, N. 1977. Cytochemical staining procedures selective for sarcotubular systems of muscle: modifications and applications. J. Ultrastruct. Res., 60, 306-327.

Hiraoka, T. and Hirai, K. 1992. Platinum-diaminobenzidine reaction and its contribution to the quantitation of cytochrome oxidase activity. J. Electron Microsc., 41, 127-129.

Mann, K.H. 1962. Leeches (Hirudinea): their structure, physiology, ecology and embryology. Pergamon Press, Oxford.

Moore, R.D., Mumaw, V. and Shomberg, M.D. 1960. Optical microscopy of ultrathin tissue sections. J. Ultrastruct. Res., 4, 113-116.

Needham, A.E. 1966. The chloragogen-pigment of earthworms. Life Sci., 5, 33-39.

Pearse, A.G.E. 1972. Histochemistry: theoretical and applied. 3rd Edn, Vol. 2. Churchill, London.

Petersen, O.H. and Maruyama, Y. 1984. Calcium-activated potassium channels and their role in secretion. Nature, 307, 693-696.

Porchet-Henneré, E. 1990. Cooperation between different coelomocyte populations during the incapsulation responses of Nereis diversicolor demonstrated by using monoclonal antibodies. J. Invert. Pathol., 56, 353-361.

Porchet-Henneré, E. and Vernet, G. 1992. Cellular immunity in an annelid (Nereis diversicolor, Polichaeta): production of melanin by a subpopulation of granulocytes. Cell Tissue Res., 269, $167-174$.

Rodriguez, A., Webster, P., Ortego, J. and Andrews, N.W. 1997. Lysosomes behave as $\mathrm{Ca}^{++}$-regulated exocytic vescicles in fibroblasts and epithelial cells. J. Cell Biol., 137, 93-104.

Sawyer, R.T. 1986. Leech Biology and Behaviour: Anatomy, Physiology and Behaviour. Oxford Science Publications, Oxford.

Shlom, J.M., Amesse, L. and Vinigradov, S.N. 1975. Subunit of Placobdella haemoglobin. Comp. Biochem. Physiol., 51, 389-392.

Soji, T., Nishizono, H., Yashiro, T. and Herbert, D.C. 1991. Cytochemistry of $\mathrm{Ca}^{++}$-dependent adenosine triphosphate $(\mathrm{Ca}-$ ATPase) in rat anterior pituitary cells. Tissue \& Cell 23, 1-6.

Tettamanti, G., Grimaldi, A., Ferrarese, R., Protasoni, M., Congiu, T. and de Eguileor, M. 2000. Hirudo medicinalis: a new model system for testing activators and inhibitors of angiogenesis. XVIIIth (New) International Congress of Zoology, Athens, Greece.

Zaharopolus, P., Wen, J.W. and Wong, J. 1998. Membranous lamellar cytoplasmic inclusion in histiocytes and mesothelial cells of serous fluid. Their relationship to phagocytosis of red blood cells. Acta Cytol., 42, 607-613. 